\title{
PRESSURES GENERATED BY LOSS OF RESISTANCE TO AIR
}

\author{
Ahmad Abotaiban MD, Ban CH Tsui MSc MD FRCPC \\ Department of Anesthesia and Perioperative Medicine, University of Western Ontario, \\ 339 Windmere Rd, London, Ontario, N6A 5A5 and Department of Anesthesiology and \\ Pain Medicine, University of Alberta, 8-120 CSB, Edmonton, AB, T6G 2G3
}

\section{INTRODUCTION}

Loss of resistance (LOR) to air has been used for years to locate the epidural space. Anesthesiologists differ in the volume of air used during LOR and are generally unaware of the pressures applied to the needle tip with these volumes. However, applying excessive pressure may generate a false pocket/space. This study investigated pressures generated by LOR with different volumes of air.

\section{METHODS}

A $10 \mathrm{~mL}$ B Braun Perifix LOR syringe was connected to a Tuohy needle attached to a pressure transducer. The transducer was connected to an arterial line pressure monitor. Pressure readings were generated by creating sustained pressure on the plunger at increasing compression ratios starting at a volume of $10 \mathrm{~mL}$ (e.g. 10 to $9 \mathrm{~mL} ; 10$ to $8 \mathrm{~mL}$ etc.). The experiment was then repeated with initial air volumes of 9, 8, 7, 6, 5, 4, 3 and 2 $\mathrm{mL}$. Each set was tested 5 times. Boyle's Law (Pressure $\mathrm{x}$ Volume $=$ constant) was used to calculate the expected pressure values from different compressions.

\section{RESULTS}

Pressures of Diffferent Compression Percentages

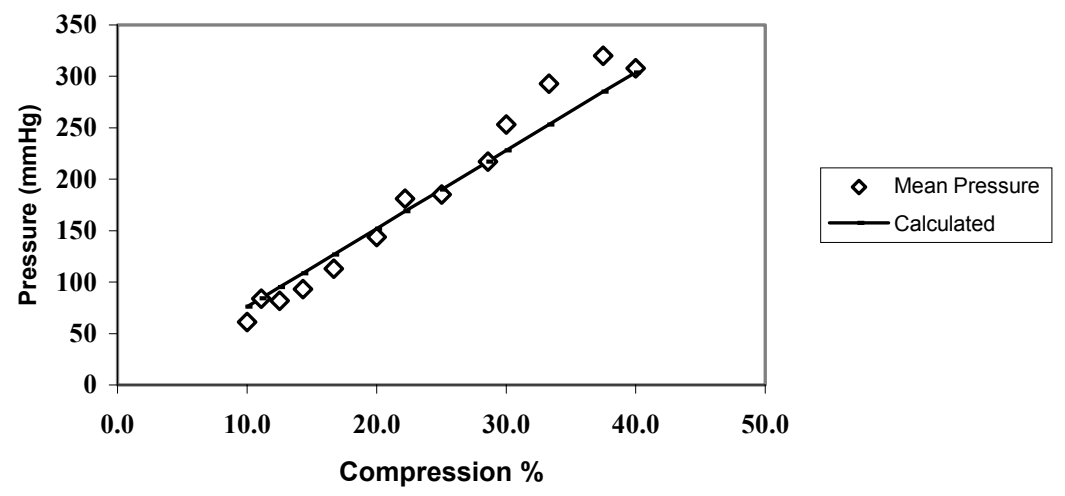

\section{DISCUSSION}

This study demonstrates the pressure generated by different compressions on a LOR syringe can be predicted by Boyle's Law. It was shown that applying approximately 300 $\mathrm{mmHg}$ of pressure during LOR successfully identified the epidural space without false LOR. ${ }^{1}$ Based on our results, the LOR syringe should not be compressed more than $35 \%$ (e.g. from approximately 6 to $4 \mathrm{~mL}$ ) to maintain a pressure below $300 \mathrm{mmHg}$.

\section{REFERENCES}

1. Anaesthesia 57:768-772. 